\title{
Análise do desempenho escolar de alunos aprovados em Conselho de Classe
}

\author{
Analysis of the students' scholar performance approved in
} the Academic Council

\author{
Jorge Alberto Rodrigues dos Santos', Angela Pellegrin Ansuj", \\ Fernando de Jesus Moreira Junior'", Angela Isabel dos Santos Dulliusiv
}

\begin{abstract}
RESUMO
Neste trabalho foi acompanhado o desempenho escolar de alunos que foram aprovados em Conselho de Classe nos anos subsequentes, nas disciplinas de Matemática, Física e Química. O estudo foi realizado no Colégio Marista Santa Maria, em Santa Maria, RS. Foram analisados três grupos de alunos que permaneceram na escola durante os três anos do ensino médio. Nesse período de 1996 a 2000, 333 alunos iniciaram e concluíram seus estudos no Colégio Marista Santa Maria, onde 75 alunos foram aprovados em Conselho de Classe. Ao todo, obteve-se 127 aprovações em Conselho de Classe. A aprovação em Conselho de Classe, para a maioria dos alunos, não comprometeu totalmente seus desempenhos nas séries seguintes. A disciplina que mais aprovou em Conselho de Classe foi Física. Nessa disciplina, o maior número de aprovações por Conselho de Classe aconteceu nas segundas e terceiras séries. Na primeira série, Matemática foi a disciplina que mais aprovou por Conselho de Classe. Química foi a disciplina que menos aprovou em Conselho de Classe. Conclui-se que as promoções em Conselho de Classe não comprometeram totalmente o desempenho desses alunos nas séries seguintes, embora grande parte deles tenham sido aprovados nas séries seguintes após estudos de recuperação terapêutica ou em Conselho de Classe.
\end{abstract}

Palavras-chave: Avaliação, aprovação, estudantes, Ensino Médio.

\begin{abstract}
In this research, it was analyzed the school performance of students, their assessment decided in the Academic Council in the subsequent years, in the discipline of Mathematics, Physics and Chemistry. The study was done at Marista School of Santa Maria, RS. It was analyzed three groups of students that have studied in the high school for three years. From 1996 to 2000, 333 students began and completed their studies at Marista School of Santa Maria, where 75 students were passed at Academic Council. In all, 127 approvals at Academic Council were obtained. The approval at Academic Council for most students did not fully compromise their performance in subsequent grades. The discipline that passed the most in Academic Council was Physics. In this discipline, the highest number of approvals at Academic Council occurred in the second and third grades. In the first grade, Mathematics was the discipline that most passed by Academic Council. Chemistry was the discipline that fewer students passed in Academic Council. It is concluded that approvals at Academic Council did not compromise totally the performance of these students in the following grades, although most of them were approved in the following grades after studies of therapeutic recovery or at Academic Council.
\end{abstract}

Key-Words: Assessment, approval, students, High School. 


\section{INTRODUÇÃO}

Segundo Werneck (1998, p. 48), a educação tradicional avaliava o aluno exclusivamente através de resultados numéricos e o método mais prático e mais divulgado era o da média aritmética dos resultados. Professores menos rígidos atribuíam notas mais amplas e os demais chegavam a atribuir notas com divisões que atingiam os centésimos. Este processo deixava os professores muito tranqüilos porque os números ditavam os critérios de justiça, eram os números que reprovavam, estabelecendo, assim, uma fórmula clara, objetiva, até mesmo cristalina, para determinar a aprovação ou reprovação de quem quer que seja.

No entendimento desse autor, essa escola avaliava apenas um prisma de todo o desenvolvimento educacional, o cognitivo. Não era relevante incluir o aspecto psicomotor e, muito menos, o afetivo, considerando que as provas mediam quase que exclusivamente o conhecimento quantitativo, o que possibilita identificar que a avaliação da escola tradicional era restrita. Hoje, quando são trabalhadas as habilidades psicomotoras e tantos outros elementos que constituem o ser humano como um todo complexo, inúmeros ex-reprovados têm êxito profissional, demonstrando o quanto o tipo de avaliação antigo era insuficiente e falho.

A antiga pedagogia dos jesuítas, embora não fosse baseada em Conselhos de Classe, dava aos professores liberdade para atribuir aos alunos esforçados, que demonstravam conhecimento durante o ano letivo, uma nota maior que a obtida na prova final. De alguma forma, já demonstravam alguma sensibilidade a mais, entendendo que o resultado de um simples exame não representava a aprendizagem do aluno ao longo de todo o ano. Hoje, existe o recurso denominado Conselho de Classe, que reúne professores e outros serviços de acompanhamento pedagógico para estudar casos de alunos que numericamente não atingiram a aprovação. Embora usada já há algum tempo, essa prática ainda não conseguiu modificar os conceitos antigos de muitos educadores. O Conselho de Classe, segundo Werneck (1998, p. 49), foi concebido exatamente com o objetivo de corrigir as distorções praticadas na avaliação dos alunos. Essa modalidade oportuniza uma análise mais ampla do educando, o que possibilita incluir na avaliação outros elementos relevantes 
do aprendizado, sobretudo em relação aos alunos com interesses já estruturados. Esse modo de avaliar permite ao educador levar em conta qualidades que detecta no aluno uma pessoa engajada no processo pedagógico.

Baseado nesse contexto, este trabalho tem como objetivo principal verificar o desempenho escolar dos alunos que frequentaram e concluíram o Ensino Médio no Colégio Marista Santa Maria, no período de 1996 a 2000, e que obtiveram aprovação por Conselho de Classe em uma ou mais séries, seguidas ou alternadamente, em uma ou mais das disciplinas analisadas: Física, Química e Matemática. Considerando que o processo avaliativo, por sua complexidade, é tema que sempre pode gerar novas reflexões, as incertezas que estão presentes na ética pedagógica do professor quando avalia, levantarão a questão: está sendo garantido ao aluno um aprender efetivo? Ele está sendo avaliado tendo por paradigma um processo de aquisição de conhecimento com qualidade reflexiva ou o olhar do professor se reduz a avaliar quantidade de informações acumulada? Assim, surgem os seguintes questionamentos:

- Entre os professores que avaliam individualmente seus alunos, há uma concepção comum dos objetivos da educação, da avaliação, de como se processa a construção do conhecimento, de quem é educando?

- A postura do educador revela coerência com o ideal de educação presente no Projeto Educativo da Escola em que trabalha?

- Há a necessidade de ter critérios e indicadores claros para o grupo trabalhar coeso em termos de educação, o que inclui a avaliação do aluno?

- Ter bem claro o que constitui o processo avaliativo possibilita ao professor entender melhor o modo de raciocinar e de aprender do aluno?

- A análise feita no Conselho de Classe, pelo grupo de professores e demais educadores, reflete critérios comuns de avaliação?

- O que o professor deve reavaliar para melhor ajudar o aluno a adquirir autonomia no processo ensino-aprendizagem?

Convivendo com essas indagações e vivenciando as duas situações: a do aluno promovido em Conselho de Classe e a do retido na série, bem como o compromisso pessoal com a prática pedagógica que requer um trabalho alicerçado em habilidades e competências para além da reprodução de informações, o pesquisador sentiu-se motivado para a realização do presente trabalho, que tem como objetivo verificar o desempenho escolar dos alunos que iniciaram e concluíram o ensino médio no 
Colégio Marista Santa Maria - RS, no período de 1996 a 2000, e que foram aprovados em Conselho de Classe em uma ou mais séries, seguida ou alternadamente, em uma ou mais das disciplinas analisadas: Física, Química e Matemática.

\section{REVISÃO DA LITERATURA}

Para Vasconcelos (1993), a avaliação que se busca tem a especificidade de acompanhamento do processo, informando alunos, professores e comunidade em que direção o desenvolvimento do aluno e do processo de ensino-aprendizagem estão se realizando, chamando-os a uma reflexão conjunta sobre essa realidade, com vistas à reelaborar e aprimorar formas de dar continuidade aos trabalhos. A avaliação é um processo contínuo e sistemático, deve ser planejada para ocorrer ao longo do processo, fornecendo feedback e permitindo a recuperação imediata quando necessária; é funcional, porque se realiza em cima de objetivos, verificando em que medida os alunos estão atingindo os objetivos previstos: a avaliação é, portanto, orientadora, pois não trabalha a exclusão; contudo, orientar o processo de aprendizagem para que possa atingir os objetivos previstos permite ao aluno conhecer seus erros e acertos, auxiliando-o a corrigir falhas; é integral, pois analisa o aluno como um todo, não apenas o cognitivo, mas, também, o aspecto afetivo e o domínio psicomotor (HAYDT, 1995).

De acordo com Haydt (1995), um dos propósitos da avaliação com função diagnóstica é informar o professor sobre os níveis de conhecimento e habilidades de seus alunos antes de iniciar o processo ensino-aprendizagem, dando-lhe elementos para determinar o quanto progrediramo quanto progrediu depois de certo tempo. Portanto, o professor precisa, antes de tudo, verificar se seus alunos dominam ou não os pré-requisitos necessários para as novas aprendizagens. É através dessa avaliação inicial, com função diagnóstica, que o professor vai determinar quais os conhecimentos e as habilidades que devem ser retomados antes de introduzir os conteúdos específicos da série ou qualquer outro que ainda não tenha sido avaliado. Isso facilita o desenvolvimento da abordagem e a assimilação e, ainda ajuda a garantir a eficácia do processo ensino-aprendizagem. 
Haydt (1995) ainda defende que um aspecto fundamental para que a avaliação cumpra sua função é que o aluno conheça os resultados de sua aprendizagem, isto é, que logo após o término de uma prova, saibam quais foram seus acertos e erros. Quanto mais imediato for esse conhecimento, mais se sentirá motivado a estudar, a corrigir as falhas e a continuar progredindo. Os especialistas concordam que "quando os alunos podem examinar suas provas e verificar o que e por que erraram, parece correto supor que muitos, se não todos, não tornarão a fazer os mesmos erros". Portanto, após uma avaliação, percebe-se que quanto antes o aluno conhecer seus acertos e erros, mais facilmente ele tende a reforçar as respostas certas, sanar as deficiências e corrigir os erros. Dessa forma, a avaliação contribui para a fixação da aprendizagem e constitui um incentivo para o aluno aprender e não apenas se preocupar com a nota.

Vasconcellos (1993) afirma que para muitos educadores, a nota serve para indicar o quanto o aluno aprendeu. Desta forma, promoverá aqueles que estiverem preparados para exercer sua profissão e reterá os que não estiverem aptos. Porém, esta hipótese é contestada. Muitas vezes, aqueles que apresentaram as melhores notas não são os melhores profissionais e aqueles que obtinham notas consideradas baixas vêm revelar-se bons profissionais.

Segundo Sant'Anna \& Werneck (1995), uma das orientações sobre Conselho de Classe é a de que ele promova a avaliação permanente e global do processo educativo, visando à consecução dos objetivos gerais e específicos da educação através de diagnóstico, aconselhamento, levantamento de soluções alternativas, elaboração de programas de recuperação, apoio, incentivo, reelaboração de objetivos, colher evidências de mudanças de comportamento dos alunos, bem como analisar as causas do baixo ou alto rendimento. Para Werneck (1998), as mudanças introduzidas no processo de educação trouxeram uma terminologia própria, de difícil compreensão por parte dos educadores e para não haver má interpretação nos Conselhos de Classe, é necessário um sólido conhecimento sobre os objetivos comportamentais como: desempenho, da evolução crescente através do curso, da melhoria gradativa dos níveis de raciocínio e os afetivos como: medir o nível de 
aceitação por parte do aluno, evoluindo de simples prontidão de resposta até o ponto mais elevado que é o da adesão, em que o aluno passa a seguir o que foi ensinado, gostando e ensinando os demais.

O Conselho de Classe reúne a Direção, a Coordenação Pedagógica, o Serviço de Orientação Educacional, professores da área e/ou professores de diferentes disciplinas da mesma série e o Professor Conselheiro, da turma em alguns momentos no conselho, todos visando, em conjunto, conhecimento sistemático da turma, bem como acompanhar e avaliar cada aluno individualmente (WERNECK, 1998, p. 56).

Reconhecendo a importância do Conselho de Classe como parte do instrumento pedagógico abrangente e valioso para acompanhamento e avaliação do processo educacional escolar, a Unidade de Pesquisa, Supervisão e Orientação Educacionais e Supervisão Técnica da Secretaria de Educação - RS, 1982, enviou documento às escolas do Sistema Estadual de Ensino, apresentando idéias e sugestões que podem ser desenvolvidas pelos Conselhos de Classe. A escola, como unidade operacional do Sistema de Ensino, é responsável pela consecução dos objetivos da Educação Nacional. Cabe à escola, em ação conjunta e integrada, verificar em que medida os objetivos propostos estão sendo atingidos. Através do Conselho de Classe, os educadores podem desenvolver um espírito crítico e refletirem em relação a resultados alcançados. O Conselho de Classe, formado por educadores, especialistas e pessoas envolvidas direta e indiretamente no processo educativo de um ou mais alunos, atuando cooperativamente, em reuniões periódicas, constitui o instrumento pedagógico de que a escola dispõe, com o objetivo de acompanhar e avaliar o desenvolvimento e o desempenho do educando como pessoa durante o processo de ensino-aprendizagem (PERINI et al., 1982).

\section{METODOLOGIA}

O presente trabalho trata de um estudo de caso que consistiu na observação do aproveitamento escolar de alunos do ensino médio do Colégio Marista Santa Maria, Santa Maria - RS, no período de 1996 a 2000. Os dados foram obtidos dos diários de classe dos alunos que permaneceram no colégio durante os três anos do ensino médio, nesse período. 
O estudo apresenta uma análise descritiva dos dados coletados na referida instituição, examinando o aproveitamento dos alunos, por meio de gráficos e tabelas, nas disciplinas de Física, Química e Matemática na(s) série(s) seguinte(s) à sua aprovação em Conselho de Classe.

\section{ANÁLISE E DISCUSSÃO DOS RESULTADOS}

A primeira turma possuía 128 alunos, que iniciou a 1ª série em 1996 e concluiu a $3^{\text {a }}$ série em 1998. A segunda turma composta por 123 alunos, iniciando em 1997 e concluindo em 1999 e a terceira formada por 82 alunos, iniciando em 1998 e concluindo em 2000.

\subsection{Desempenho escolar da primeira turma}

Dos 128 alunos da primeira turma, $62(48,4 \%)$ foram aprovados por média (AM) em todas as três disciplinas avaliadas, e os demais $66(51,6 \%)$ foram aprovados na Recuperação Terapêutica (RT) em pelo menos uma disciplina, sendo que, dentre esses, 26 (20,3\%) foram aprovados por CC em pelo menos uma disciplina. Todos os alunos que foram aprovados por CC também tinham sido aprovados por RT pelo menos uma vez em alguma disciplina, o que sugere que são alunos com baixo desempenho. Na Tabela 1 é mostrado o número de alunos segundo o número de aprovações por CC, que ao todo foram 40. Dentre os alunos aprovados por CC, 18 $(69,2 \%)$ foram aprovados somente uma vez por CC. Observa-se que um aluno foi aprovado por CC 5 vezes, sendo 3 vezes em física, 1 vez em química ( $3^{\mathrm{a}}$ série) e 1 vez em matemática ( $3^{\mathrm{a}}$ série).

Tabela 1 - Número de alunos aprovados por Conselho de Classe na primeira turma

\begin{tabular}{lc}
\hline Aprovações por Conselho de Classe & Número de alunos \\
\hline Nenhuma & 62 \\
Uma & 18 \\
Duas & 4 \\
Três & 3 \\
Cinco & 1 \\
\hline Total & 128 \\
\hline
\end{tabular}


Na Figura 1 é apresentado o número de aprovações por CC por série e por disciplina, sendo no total 40. Observa-se que Física e Matemática foram as disciplinas com mais aprovações por CC, 17 e 15, respectivamente. Observa-se também um aumento gradativo de aprovações por CC em Física e Química, porém um decréscimo em Matemática, ao longo dos anos. No geral, no entanto, há um aumento gradativo de aprovações por CC ao longo do tempo, sendo 9 na $1^{\text {a }}$ série, 14 na $2^{\text {a }}$ série e 17 na $3^{\mathrm{a}}$ série.

Figura 1 - Número de aprovações por Conselho de Classe (CC) na primeira turma segundo a série e a disciplina

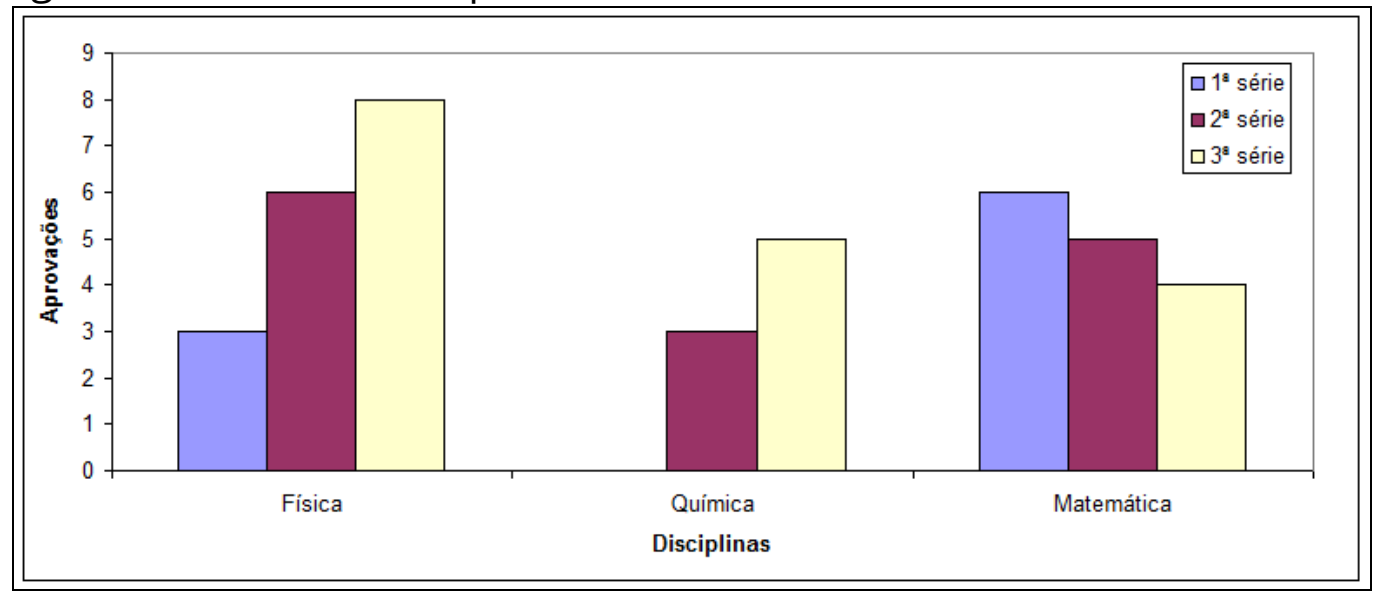

Na Tabela 2 é mostrado que dentre os 26 alunos que foram aprovados por CC em pelo menos uma disciplina, 19 (73,1\%) foram aprovados em CC em somente uma disciplina. Destaca-se o fato que não houve nenhum registro de aprovação somente em Física e Matemática simultaneamente, mas três em Física, Química e Matemática, simultaneamente.

Tabela 2 - Número de alunos aprovados por Conselho de Classe por disciplina na primeira turma

\begin{tabular}{lc}
\hline Disciplina(s) & Número de alunos \\
\hline Somente em Física & 8 \\
Somente em Química & 1 \\
Somente em Matemática & 1 \\
Somente em Física e Química & 3 \\
Somente em Física e Matemática & 0 \\
Somente em Química e Matemática & 1 \\
Em todas as disciplinas & 3 \\
\hline Total & 26 \\
\hline
\end{tabular}


Na Tabela 3 é mostrado que dentre os 26 alunos que foram aprovados por CC em pelo menos uma disciplina, $21(80,1 \%)$ foram aprovados em CC em somente uma série. Destaca-se um aluno que foi aprovado por CC em todas as séries.

Tabela 3 - Número de alunos aprovados por Conselho de Classe por série na primeira turma

\begin{tabular}{lc}
\hline Série & Número de alunos \\
\hline Somente na $1^{\text {a }}$ série & 6 \\
Somente na $2^{\mathrm{a}}$ série & 8 \\
Somente na $3^{\mathrm{a}}$ série & 7 \\
Somente na $1^{\mathrm{a}}$ e na $2^{\mathrm{a}}$ séries & 1 \\
Somente na $1^{\mathrm{a}}$ e na $3^{\mathrm{a}}$ séries & 1 \\
Somente na $2^{\mathrm{a}}$ e na $3^{\mathrm{a}}$ séries & 2 \\
Em todas as séries & 1 \\
\hline Total & 26 \\
\hline
\end{tabular}

\subsubsection{Disciplina de Física}

Na Figura 2 é apresentado o número de aprovações segundo a forma de aprovação e por ano na disciplina de Física. Observa-se que há algumas pequenas variações no número de AM e nas aprovações por RT, mas as aprovações por CC quase triplicaram da $1^{\text {a }}$ para a $3^{\mathrm{a}}$ série.

Figura 2 - Número de aprovações da primeira turma segundo a forma de aprovação e a série na disciplina de Física.

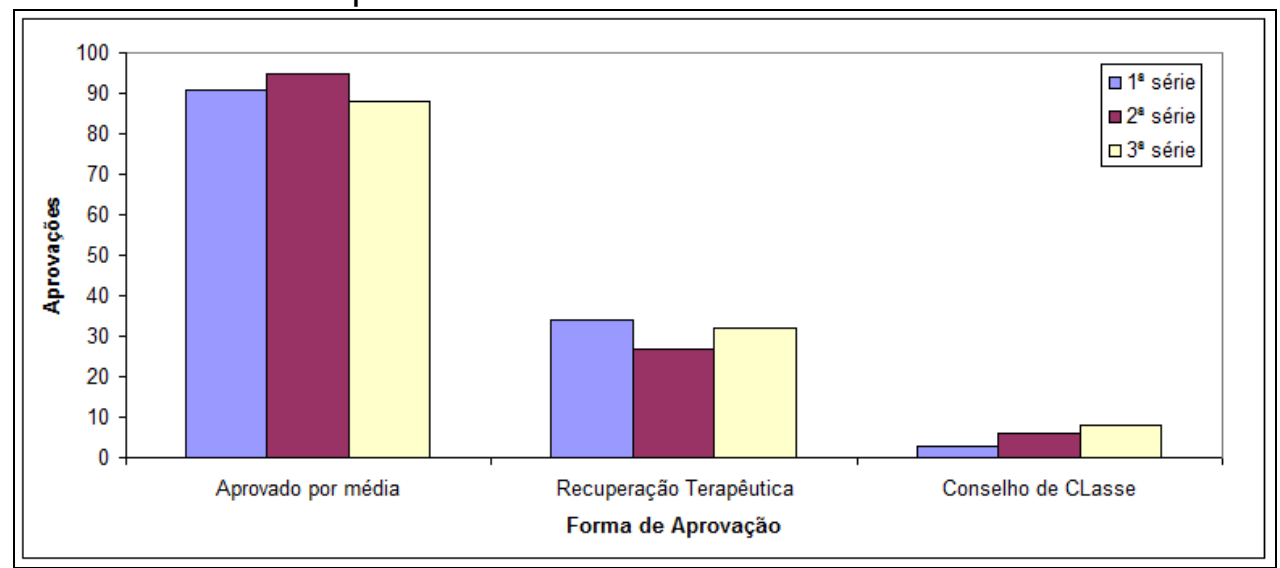

Na Tabela 4 é apresentado o desempenho dos alunos em Física durante as três séries. Observa-se que dos 128 alunos da primeira turma, 66 (51,6\%) foram aprovados por média em Física em todas as séries, 59 (46,1\%) foram aprovados na RT pelo menos em uma série, e $14(10,9 \%)$ foram aprovados no CC pelo menos em uma série. 
Tabela 4 - Desempenho dos alunos da primeira turma em Física durante as três séries

\begin{tabular}{lcccc}
\hline $1^{\text {a }}$ série & $2^{\text {a }}$ série & $3^{\text {a }}$ série & Número de alunos & Aprovações por CC \\
\hline AM & AM & AM & 66 & 0 \\
AM & AM & RT & 6 & 0 \\
AM & RT & AM & 6 & 0 \\
RT & AM & AM & 13 & 0 \\
AM & RT & RT & 7 & 0 \\
RT & AM & RT & 7 & 0 \\
RT & RT & AM & 3 & 0 \\
RT & RT & RT & 6 & 0 \\
CC & AM & RT & 1 & 1 \\
AM & CC & RT & 3 & 1 \\
RT & CC & RT & 2 & 1 \\
AM & AM & CC & 2 & 1 \\
AM & RT & CC & 1 & 1 \\
RT & RT & CC & 3 & 1 \\
CC & RT & CC & 1 & 2 \\
CC & CC & CC & 1 & 3 \\
\hline AM: Aprovado por Média; CC: Conselho de Classe; RT: Recuperação Terapêutica
\end{tabular}

Com relação aos alunos aprovados por CC em Física, observa-se que: um aluno foi aprovado em CC em todas as séries; três alunos foram aprovados após estudos de RT na $1^{\text {a }}$ e $2^{\text {a }}$ séries e em CC na $3^{\text {a }}$ série; três alunos foram aprovados por média na $1^{\text {a }}$ série, em CC na $2^{\mathrm{a}}$ e após estudos de RT na $3^{\mathrm{a}}$ série; dois alunos foram aprovados após estudos de RT na $1^{\mathrm{a}}$ e $3^{\mathrm{a}}$ séries e em CC na $2^{\mathrm{a}}$ série; dois alunos foram aprovados por média na $1^{\text {a }}$ e $2^{\text {a }}$ séries e em CC na $3^{\text {a }}$ série; um aluno foi aprovado em CC na $1^{\text {a }}$ série, por média na $2^{\mathrm{a}}$ e após, estudos de RT, na $3^{\mathrm{a}}$ série; um aluno foi aprovado por média na $1^{\text {a }}$ série, após estudos de RT na $2^{\text {a }}$ e, em $C C$, na $3^{\text {a }}$ série; e um aluno foi aprovado em CC na $1^{\mathrm{a}}$ e $3^{\mathrm{a}}$ séries e após estudos de RT na $2^{\mathrm{a}}$ série.

\subsubsection{Disciplina de Química}

Na Figura 3 é apresentado o número de aprovações segundo a forma de aprovação e por ano na disciplina de Química. Observa-se que há algumas pequenas variações no número de AM. As aprovações por RT foram maiores na $1^{\text {a }}$ e na $3^{\mathrm{a}}$ série e houveram poucas aprovações por CC, sendo nenhuma na $1^{\text {a }}$ série. De um modo geral, parece que a $3^{a}$ série foi a mais difícil para os alunos. 
Figura 3 - Número de aprovações da primeira turma segundo a forma de aprovação e a série na disciplina de Química.

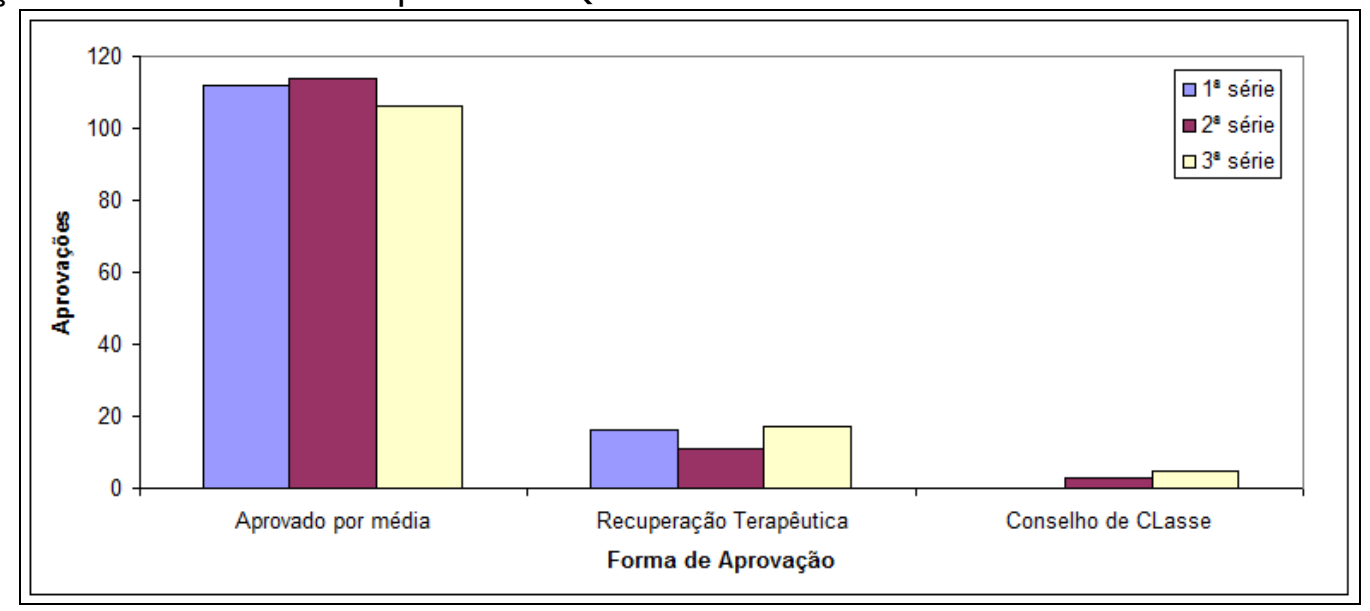

Na Tabela 5 é apresentado o desempenho dos alunos em Química durante as três séries. Observa-se que dos 128 alunos da primeira turma, 95 (74,2\%) foram aprovados por média em Química em todas as séries, 31 (24,2\%) foram aprovados na RT pelo menos em uma série, e 8 (6,2\%) foram aprovados no CC pelo menos em uma série.

Tabela 5 - Desempenho dos alunos da primeira turma em Química durante as três séries

\begin{tabular}{lcccc}
\hline $1^{\text {a }}$ série & $2^{\text {a }}$ série & 3 $^{\text {a série }}$ & Número de alunos & Aprovações por CC \\
\hline AM & AM & AM & 95 & 0 \\
AM & AM & RT & 7 & 0 \\
RT & AM & AM & 5 & 0 \\
AM & RT & AM & 4 & 0 \\
AM & RT & RT & 2 & 0 \\
RT & AM & RT & 5 & 0 \\
RT & RT & RT & 2 & 0 \\
AM & CC & AM & 1 & 1 \\
AM & CC & RT & 1 & 1 \\
RT & CC & AM & 1 & 1 \\
AM & RT & CC & 1 & 1 \\
AM & AM & CC & 1 & 1 \\
RT & AM & CC & 1 & 1 \\
RT & RT & CC & 2 & 1 \\
\hline AM: Aprovado por Média; CC: Conselho de Classe; RT: Recuperação Terapêutica
\end{tabular}

Com relação aos alunos aprovados por CC em Química, observa-se que: dois alunos foram aprovados após estudos de RT na $1^{\text {a }}$ e $2^{\text {a }}$ séries e, em CC, na $3^{\text {a }}$ série; um aluno foi aprovado após estudos de RT na $1^{\text {a }}$ série, em CC na $2^{\mathrm{a}}$ e, por média, na $3^{\mathrm{a}}$ série; um aluno foi aprovado por média na $1^{\mathrm{a}}$ série, em CCe na $2^{\mathrm{a}}$ e, após estudos 
de RT, na $3^{\mathrm{a}}$ série; um aluno foi aprovado por média na $1^{\text {a }}$ série, após estudos de RT na $2^{\mathrm{a}}$ e, em CC, na $3^{\mathrm{a}}$ série; um aluno foi aprovado após estudos de RT na $1^{\text {a }}$ série,por média na $2^{\mathrm{a}}$ e, em CC na $3^{\mathrm{a}}$ série; um aluno foi aprovado por média na $1^{\mathrm{a}}$ e $3^{\mathrm{a}}$ séries e, em CC, na $2^{\mathrm{a}}$ série; e um aluno foi aprovado por média na $1^{\mathrm{a}}$ e $2^{\mathrm{a}}$ séries e, em CC, na $3^{\mathrm{a}}$ série.

\subsubsection{Disciplina de Matemática}

Na Figura 4 é apresentado o número de aprovações segundo a forma de aprovação e por ano na disciplina de Matemática. Observa-se que há algumas pequenas variações no número de CC e uma diferença mais visível no número de AM e aprovações por RT na $1^{\text {a }}$ série, sugerindo que essa série pode ter sido mais difícil do que as demais.

Figura 4 - Número de aprovações da primeira turma segundo a forma de aprovação e por a na disciplina de Matemática

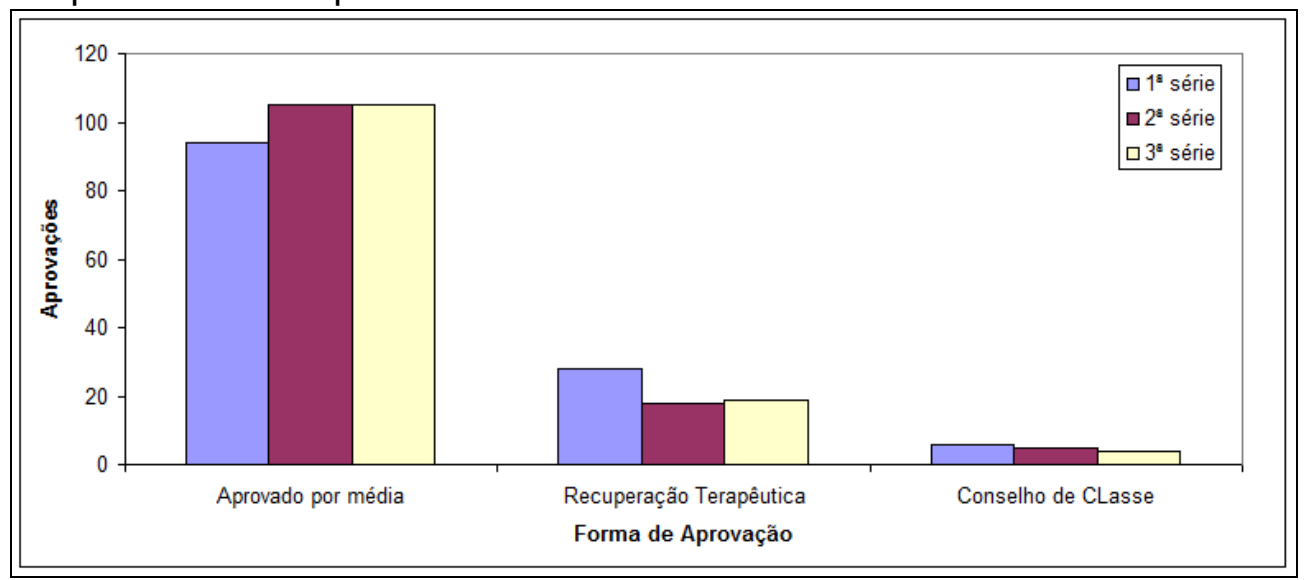

Na Tabela 6 é apresentado o desempenho dos alunos em Matemática durante as três séries. Observa-se que dos 128 alunos da primeira turma, 80 (62,5\%) foram aprovados por média em Matemática em todas as séries, 46 (35,9\%) foram aprovados na RT pelo menos em uma série, e $14(10,9 \%)$ foram aprovados no CC pelo menos em uma série. 
Tabela 6 - Desempenho dos alunos da primeira turma em Matemática durante as três séries

\begin{tabular}{lcccc}
\hline $1^{\text {a }}$ série & $2^{\text {a }}$ série & $3^{\text {a }}$ série & Número de alunos & Aprovações por CC \\
\hline RT & AM & AM & 80 & 0 \\
RT & AM & RT & 3 & 0 \\
RT & RT & AM & 3 & 0 \\
RT & RT & RT & 4 & 0 \\
RT & AM & AM & 12 & 0 \\
RT & AM & RT & 7 & 0 \\
RT & RT & AM & 3 & 0 \\
RT & RT & RT & 2 & 0 \\
CC & AM & AM & 1 & 1 \\
CC & AM & RT & 1 & 1 \\
CC & RT & AM & 2 & 1 \\
CC & RT & RT & 1 & 1 \\
RT & CC & RT & 1 & 1 \\
RT & CC & AM & 3 & 1 \\
RT & AM & CC & 1 & 1 \\
RT & RT & CC & 3 & 1 \\
CC & CC & AM & 1 & 2 \\
\hline AM: Aprovado por Média: CC: Conselho de Classe: RT: Recuperaç̃o Terapêutica
\end{tabular}

Com relação aos alunos aprovados por CC em Matemática, observa-se que: três alunos foram aprovados após estudos de RT na $1^{\text {a }}$ e $2^{\text {a }}$ séries e, em CC, na $3^{\text {a }}$ série; um aluno foi aprovado em CC na $1^{\text {a }}$ série, por média na $2^{\mathrm{a}}$ e, após estudos de RT, na $3^{\mathrm{a}}$ série; um aluno foi aprovado após estudos de RT na $1^{\text {a }}$ e $3^{\mathrm{a}}$ séries e, em CC, na $2^{\mathrm{a}}$ série; três alunos foram aprovados por média na $1^{\text {a }}$ e $3^{\mathrm{a}}$ séries e, em CC, na $2^{\mathrm{a}}$ série; dois alunos foram aprovados em CC na $1^{\text {a }}$ série, após estudos de RT na $2^{\text {a }}$ série e, por média, na $3^{\mathrm{a}}$; um aluno foi aprovado em CC na $1^{\mathrm{a}}$ série e, por média, na $2^{\mathrm{a}}$ e $3^{\mathrm{a}}$ séries; um aluno foi aprovado em CC na $1^{\text {a }}$ e $2^{\text {a }}$ séries e, por média, na $3^{\mathrm{a}}$ série; um aluno foi aprovado por média na $1^{\mathrm{a}}$ e $2^{\mathrm{a}}$ séries e, em CC, na $3^{\mathrm{a}}$ série; um aluno foi aprovado em CC na $1^{\text {a }}$ série e, após estudos de RT, na $2^{\mathrm{a}}$ e $3^{\mathrm{a}}$ séries.

\subsection{Desempenho escolar da segunda turma}

Dos 123 alunos da segunda turma, 63 (51,2\%) foram aprovados por média (AM) em todas as três disciplinas avaliadas, $58(47,1 \%)$ foram aprovados na Recuperação Terapêutica (RT) em pelo menos uma disciplina e $28(22,8 \%)$ foram aprovados por CC em pelo menos uma disciplina. Quase todos os alunos que foram aprovados por CC (26) também tinham sido aprovados por RT pelo menos uma vez em alguma disciplina, o que sugere que são alunos com baixo desempenho. A Tabela 7 mostra o 
número de alunos segundo o número de aprovações por CC, que ao todo foram 55. Dentre os alunos aprovados por CC, 14 (53,8\%) foram aprovados somente uma vez por CC. Observa-se que um aluno foi aprovado por CC 5 vezes, sendo 2 vezes em física ( $1^{\mathrm{a}}$ e $3^{\mathrm{a}}$ séries), 2 vezes em química ( $2^{\mathrm{a}}$ e $3^{\mathrm{a}}$ séries) e 1 vez em matemática ( $3^{\mathrm{a}}$ série).

Tabela 7 - Número de alunos aprovados por Conselho de Classe na segunda turma

\begin{tabular}{lc}
\hline Aprovações por Conselho de Classe & Número de alunos \\
\hline Nenhuma & 95 \\
Uma & 14 \\
Duas & 6 \\
Três & 4 \\
Quatro & 3 \\
Cinco & 1 \\
\hline Total & 123 \\
\hline
\end{tabular}

Na Figura 5 é apresentado o número de aprovações por CC por série e por disciplina, sendo no total 55. Observa-se que Física e Matemática foram as disciplina com mais aprovações por CC, 26 e 16, respectivamente. Observa-se também um aumento gradativo de aprovações por CC em Física, um aumento e depois uma queda em Matemática, e uma queda em Química (da $2^{\mathrm{a}}$ para a $3^{\mathrm{a}}$ série), ao longo dos anos. No geral, no entanto, o número de aprovações por CC ao longo do tempo, duplica da $1^{\text {a }}$ para a $2^{\mathrm{a}}$ série, caindo um pouco na $3^{\mathrm{a}}$ série, sendo 12 na $1^{\mathrm{a}}$ série, 24 na $2^{\mathrm{a}}$ série e 19 na $3^{\mathrm{a}}$ série.

Figura 5 - Número de aprovações por Conselho de Classe (CC) na segunda turma segundo a série e a disciplina.

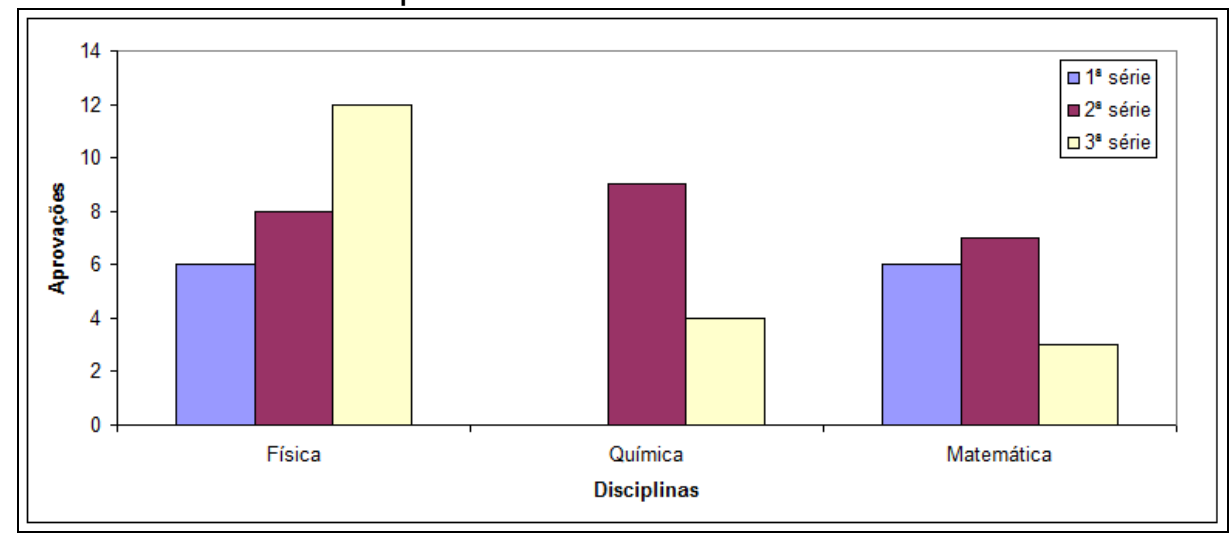


Na Tabela 8 é mostrado que dentre os 28 alunos que foram aprovados por CC em pelo menos uma disciplina, 14 (50,0\%) foram aprovados em CC em somente uma disciplina. Destaca-se a ocorrência de 7 alunos (25,0\%) com aprovação em CC somente em Física e Matemática simultaneamente, e três em Física, Química e Matemática simultaneamente.

Tabela 8 - Número de alunos aprovados por Conselho de Classe por disciplina na segunda turma

\begin{tabular}{lc}
\hline Disciplina(s) & Número de alunos \\
\hline Somente em Física & 5 \\
Somente em Química & 4 \\
Somente em Matemática & 5 \\
Somente em Física e Química & 3 \\
Somente em Física e Matemática & 7 \\
Somente em Química e Matemática & 1 \\
Em todas as disciplinas & 3 \\
\hline Total & 28 \\
\hline
\end{tabular}

Na Tabela 9 é mostrado que dentre os 28 alunos que foram aprovados por CC em pelo menos uma disciplina, 18 (64,3\%) foram aprovados em CC em somente uma série. Destaca-se que dois alunos foram aprovados por CC em todas as séries.

Tabela 9 - Número de alunos aprovados por Conselho de Classe por série na segunda turma

\begin{tabular}{lc}
\hline Série(s) & Número de alunos \\
\hline Somente na $1^{\text {a }}$ série & 2 \\
Somente na $2^{\mathrm{a}}$ série & 8 \\
Somente na $3^{\mathrm{a}}$ série & 8 \\
Somente na $1^{\mathrm{a}}$ e na $2^{\mathrm{a}}$ séries & 3 \\
Somente na $1^{\mathrm{a}}$ e na $3^{\mathrm{a}}$ séries & 1 \\
Somente na $2^{\mathrm{a}}$ e na $3^{\mathrm{a}}$ séries & 4 \\
Em todas as séries & 2 \\
\hline Total & \\
\hline
\end{tabular}

\subsubsection{Disciplina de Física}

Na Figura 6 é apresentado o número de aprovações segundo a forma de aprovação e por ano na disciplina de Física. Observa-se que na $2^{\text {a }}$ série houve um aumento considerável de aprovações por RT como consequente queda do número de aprovações por média. Quanto às aprovações por CC, elas duplicaram da $1^{\text {a }}$ para a $3^{\mathrm{a}}$ série. 
Figura 6 - Número de aprovações da segunda turma segundo a forma de aprovação e a série na disciplina de Física.

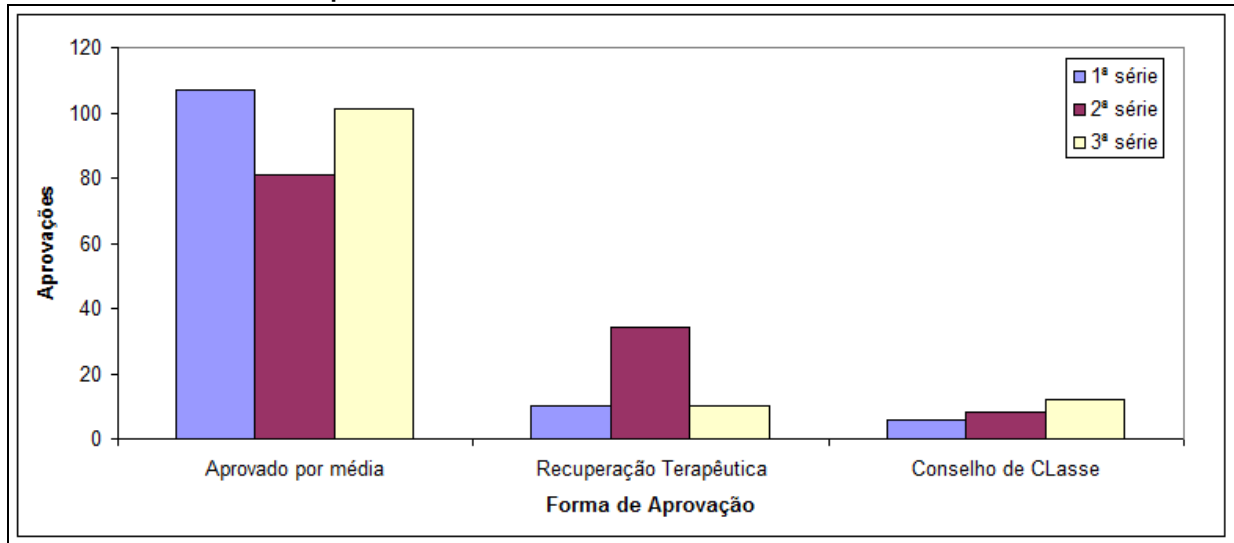

Na Tabela 10 é apresentado o desempenho dos alunos em Física durante as três séries. Observa-se que dos 123 alunos da segunda turma, 72 (58,5\%) foram aprovados por média em Física em todas as séries, 59 (26,0\%) foram aprovados na RT pelo menos em uma série, e $19(15,4 \%)$ foram aprovados no CC pelo menos em uma série.

Tabela 10 - Desempenho dos alunos da segunda turma em Física durante as três séries

\begin{tabular}{lcccc}
\hline $1^{\text {a }}$ série & $2^{\text {a }}$ série & $3^{\text {a }}$ série & Número de alunos & Aprovações por CC \\
\hline AM & AM & AM & 72 & 0 \\
AM & AM & RT & 2 & 0 \\
AM & RT & AM & 21 & 0 \\
AM & RT & RT & 3 & 0 \\
RT & AM & AM & 2 & 0 \\
RT & RT & RT & 1 & 0 \\
RT & AM & RT & 1 & 0 \\
RT & RT & AM & 2 & 0 \\
CC & AM & AM & 1 & 1 \\
AM & CC & AM & 1 & 1 \\
AM & CC & RT & 2 & 1 \\
RT & CC & AM & 2 & 1 \\
AM & AM & CC & 2 & 1 \\
AM & RT & CC & 3 & 1 \\
RT & AM & CC & 1 & 1 \\
RT & RT & CC & 1 & 1 \\
CC & CC & RT & 1 & 2 \\
AM & CC & CC & 1 & 2 \\
CC & RT & CC & 3 & 2 \\
CC & CC & CC & 1 & 3 \\
\hline
\end{tabular}

AM: Aprovado por Média; CC: Conselho de Classe; RT: Recuperação Terapêutica 
Com relação aos alunos aprovados por CC em Física, observa-se que: um aluno foi aprovado por média na $2^{\mathrm{a}}$ e $3^{\mathrm{a}}$ séries e em CC na $1^{\mathrm{a}}$ série; um aluno foi aprovado por média na $1^{\text {a }}$ e $3^{\text {a }}$ séries e, em CC, na $2^{\mathrm{a}}$ série; dois alunos foram aprovados por média na $1^{\mathrm{a}}$ série, em CC na $2^{\mathrm{a}}$ e, após estudos de RT, na $3^{\mathrm{a}}$ série; dois alunos foram aprovados por média na $3^{\mathrm{a}}$ série, em CC na $2^{\mathrm{a}}$ e, após estudos de RT, na $1^{\text {a }}$ série; dois alunos foram aprovados por média na $1^{\text {a }}$ e $2^{\text {a }}$ séries e em CC na $3^{\text {a }}$ série; três alunos foram aprovados por média na $1^{\text {a }}$ série, após estudo de RT na $2^{\mathrm{a}}$ e, em CC, na $3^{\mathrm{a}}$ série; um aluno foi aprovado após estudos de RT na $1^{\text {a }}$ série, por média na $2^{\mathrm{a}}$ e, em CC, na $3^{\mathrm{a}}$ série; um aluno foi aprovado após estudos de RT na $1^{\mathrm{a}}$ e $2^{\mathrm{a}}$ séries e, em CC, na $3^{\mathrm{a}}$ série; um aluno foi aprovado por média na $1^{\text {a }}$ série e, em CC, na $2^{\text {a }}$ e $3^{\text {a }}$ séries; um aluno foi aprovado após estudos de RT na $1^{\text {a }}$ série, em CC na $2^{\mathrm{a}}$ e, por média, na $3^{\mathrm{a}}$ série; três alunos foram aprovados em CC na $1^{\text {a }}$ e $3^{\text {a }}$ séries e, após estudos de RT, na $2^{\mathrm{a}}$ série; um aluno foi aprovado em CC nas três séries.

\subsubsection{Disciplina de Química}

Na Figura 7 é apresentado o número de aprovações segundo a forma de aprovação e o ano na disciplina de Química. Observa-se que na $2^{\mathrm{a}}$ série houve um aumento de aprovações por RT como consequente queda de AM. Houve poucas aprovações por $\mathrm{CC}$, sendo nenhuma na $1^{\mathrm{a}}$ série. De um modo geral, a $2^{\mathrm{a}}$ série foi a mais difícil para os alunos.

Figura 7 - Número de aprovações da segunda turma segundo a forma de aprovação e a série na disciplina de Química.

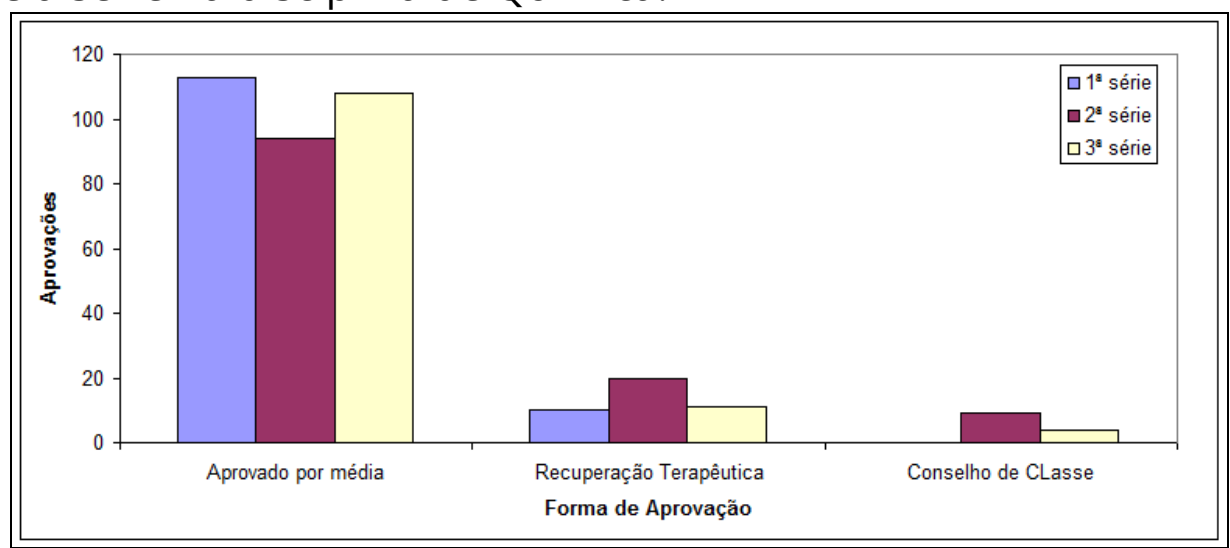

Na Tabela 11 é apresentado o desempenho dos alunos em Química durante as três séries. Observa-se que dos 128 alunos da primeira turma, 95 (74,2\%) foram 
aprovados por média em Química em todas as séries, 31 (24,2\%) foram aprovados na RT pelo menos em uma série, e 8 (6,2\%) foram aprovados no CC pelo menos em uma série.

Tabela 11 - Desempenho dos alunos da segunda turma em Química durante as três séries

\begin{tabular}{lcccc}
\hline $1^{\text {a }}$ série & $2^{\text {a }}$ série & 3 $^{\text {a série }}$ & Número de alunos & Aprovações por CC \\
\hline AM & AM & AM & 84 & 0 \\
AM & AM & RT & 6 & 0 \\
AM & RT & AM & 14 & 0 \\
AM & RT & RT & 2 & 0 \\
RT & AM & AM & 3 & 0 \\
RT & RT & AM & 1 & 0 \\
RT & RT & RT & 2 & 0 \\
RT & CC & AM & 2 & 1 \\
RT & CC & RT & 1 & 1 \\
AM & CC & AM & 4 & 1 \\
AM & AM & CC & 1 & 1 \\
AM & RT & CC & 1 & 1 \\
AM & CC & CC & 1 & 2 \\
RT & CC & CC & 1 & 2 \\
\hline AM: Aprovado por Média; CC: Conselho de Classe; RT: Recuperação Terapêutica
\end{tabular}

Com relação aos alunos aprovados por CC em Química, observa-se que: dois alunos foram aprovados após estudos de RT na $1^{\text {a }}$ série, em CC na $2^{\text {a }}$ série e, por média, na $3^{\mathrm{a}}$ série; um aluno foi aprovado após estudos de RT na $1^{\text {a }}$ e $3^{\mathrm{a}}$ séries e, em CC, na $2^{\text {a }}$ série; quatro alunos foram aprovados por média na $1^{\text {a }}$ e $3^{\text {a }}$ séries e, em CC, na $2^{\mathrm{a}}$ série; um aluno foi aprovado por média na $1^{\mathrm{a}}$ e $2^{\mathrm{a}}$ séries e, em CC, na $3^{\mathrm{a}}$ série; um aluno foi aprovado por média na $1^{\text {a }}$ série, após estudos de RT na $2^{\mathrm{a}}$ e, em CC, na $3^{\mathrm{a}}$ série; um aluno foi aprovado por média na $1^{\mathrm{a}}$ série e, em CC, na $2^{\mathrm{a}}$ e $3^{\mathrm{a}}$ séries; e um aluno foi aprovado após estudos de RT na $1^{\text {a }}$ série e, em CC, na $2^{\mathrm{a}}$ e $3^{\mathrm{a}}$ séries.

\subsubsection{Disciplina de Matemática}

Na Figura 8 é apresentado o número de aprovações segundo a forma de aprovação e por ano na disciplina de Matemática. Observa-se que não houve muita diferença entre a $2^{\mathrm{a}}$ e a $3^{\mathrm{a}}$ série em termos de forma de aprovação, no entanto, na $3^{\mathrm{a}}$ série houve um aumento visível de AM e uma queda em aprovações por RT e em CC, sugerindo que essa série pode ter sido mais fácil do que as demais. 
Figura 8 - Número de aprovações da segunda turma segundo a forma de aprovação e a série na disciplina de Matemática.

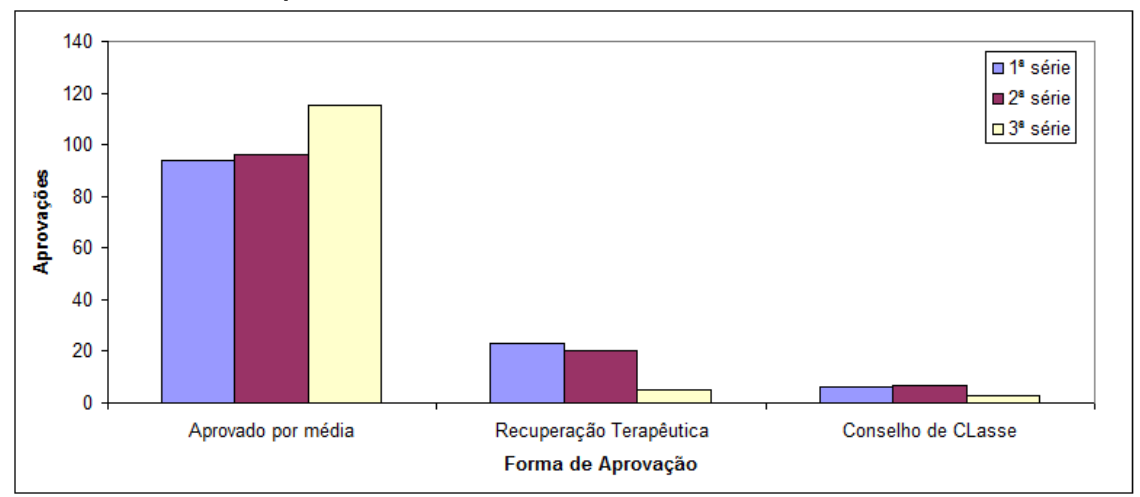

Na Tabela 12 é apresentado o desempenho dos alunos em Matemática durante as três séries. Observa-se que dos 128 alunos da primeira turma, 80 (62,5\%) foram aprovados por média em Matemática em todas as séries, 46 (35,9\%) foram aprovados na RT pelo menos em uma série, e $14(10,9 \%)$ foram aprovados no CC pelo menos em uma série.

Tabela 12 - Desempenho dos alunos da segunda turma em Matemática durante as três séries

\begin{tabular}{lcccc}
\hline $1^{\text {a }}$ série & $2^{\text {a }}$ série & $3^{\text {a }}$ série & Número de alunos & Aprovações por CC \\
\hline AM & AM & AM & 82 & 0 \\
AM & RT & AM & 10 & 0 \\
RT & AM & AM & 12 & 0 \\
RT & RT & AM & 2 & 0 \\
RT & RT & RT & 2 & 0 \\
CC & RT & AM & 4 & 1 \\
CC & RT & RT & 1 & 1 \\
RT & CC & AM & 3 & 1 \\
RT & CC & RT & 1 & 1 \\
AM & CC & AM & 2 & 1 \\
RT & AM & CC & 2 & 1 \\
RT & RT & CC & 1 & 1 \\
CC & CC & RT & 1 & 2 \\
\hline
\end{tabular}

AM: Aprovado por Média; CC: Conselho de Classe; RT: Recuperação Terapêutica

Com relação aos alunos aprovados por CC em Matemática, observa-se que: quatro alunos foram aprovados em CC na $1^{\mathrm{a}}$ série, após estudos de RT na $2^{\mathrm{a}}$ e, por média, na $3^{\mathrm{a}}$ série; um aluno foi aprovado em CC na $1^{\text {a }}$ série, após estudos de RT na $2^{\mathrm{a}}$ e na $3^{a}$ série; três alunos foram aprovados após estudos de RT na $1^{\text {a }}$ série, em CC na $2^{\mathrm{a}}$ e, por média, na $3^{\mathrm{a}}$ série; um aluno foi aprovado após estudos de RT na $1^{\mathrm{a}}$ e $3^{\mathrm{a}}$ séries e, em CC, na $2^{\mathrm{a}}$ série; dois alunos foram aprovados por média na $1^{\mathrm{a}}$ e $3^{\mathrm{a}}$ séries 
e, em CC, na $2^{\text {a }}$ série; dois alunos foram aprovados após estudos de RT na $1^{\text {a }}$ série, por média na $2^{\mathrm{a}}$ série e, em CC, na $3^{\mathrm{a}}$ série; um aluno foi aprovado após estudos de RT na $1^{\mathrm{a}}$ e $2^{\mathrm{a}}$ séries e, em CC, na $3^{\mathrm{a}}$ série; e um aluno foi aprovado em CC e na $1^{\text {a }}$ e $2^{\mathrm{a}}$ séries e, após estudos de RT, na $3^{\mathrm{a}}$ série.

\subsection{Desempenho escolar da terceira turma}

Dos 82 alunos da terceira turma, 41 (50,0\%) foram aprovados por média (AM) em todas as três disciplinas avaliadas, 38 (46,3\%) foram aprovados na Recuperação Terapêutica (RT) em pelo menos uma disciplina e $21(25,6 \%)$ foram aprovados por CC em pelo menos uma disciplina. Ainda houve um aluno reprovado em duas disciplinas da $3^{\text {a }}$ série. Quase todos os alunos que foram aprovados por CC (18) também tinham sido aprovados por RT pelo menos uma vez em alguma disciplina, o que sugere que são alunos com baixo desempenho. A Tabela 13 mostra o número de alunos segundo o número de aprovações por CC, que ao todo foram 32. Dentre os alunos aprovados por CC, 13 (40,6\%) foram aprovados somente uma vez por CC. Observa-se que um aluno foi aprovado por CC 5 vezes, sendo 2 vezes em física ( $1^{\text {a }}$ e $3^{\mathrm{a}}$ séries), 2 vezes em química ( $2^{\mathrm{a}}$ e $3^{\mathrm{a}}$ séries) e 1 vez em matemática ( $3^{\mathrm{a}}$ série).

Tabela 13 - Número de alunos aprovados por Conselho de Classe na terceira turma

\begin{tabular}{lc}
\hline Aprovações por Conselho de Classe & Número de alunos \\
\hline Nenhuma & 61 \\
Uma & 13 \\
Duas & 6 \\
Três & 1 \\
Quatro & 1 \\
\hline Total & 82 \\
\hline
\end{tabular}

A Figura 9 apresenta o número de aprovações por CC por série e por disciplina, sendo no total 32. Observa-se que Física e Matemática foram as disciplina com mais aprovações por CC, 17 e 13, respectivamente. Percebe-se que essa turma teve um comportamento bem diferente das demais com relação às aprovações por CC. Destaca-se o resultado da $2^{\text {a }}$ série com 28 (87,5\%) aprovações por CC, enquanto que na $3^{\mathrm{a}}$ série não houve nenhuma aprovação por CC. 
Figura 9 - Número de aprovações por Conselho de Classe (CC) na terceira turma segundo a série e a disciplina

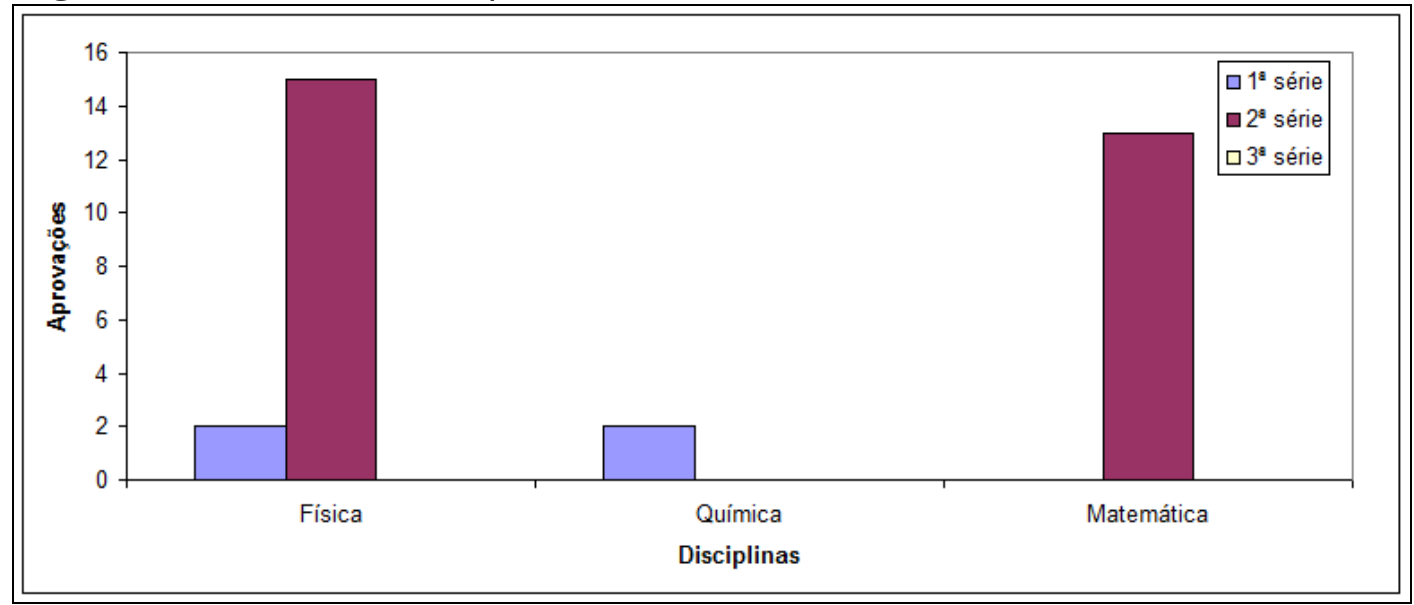

Na Tabela 14 é mostrado que dentre os 21 alunos que foram aprovados por CC em pelo menos uma disciplina, 12 (57,1\%) foram aprovados em CC em somente uma disciplina. Destaca-se a ocorrência de 7 alunos $(33,3 \%)$ com aprovação em CC somente em Física e Matemática simultaneamente, e um em Física, Química e Matemática simultaneamente.

Tabela 14 - Número de alunos aprovados por Conselho de Classe por disciplina na terceira turma

\begin{tabular}{lc}
\hline Disciplina(s) & Número de alunos \\
\hline Somente em Física & 7 \\
Somente em Química & 1 \\
Somente em Matemática & 5 \\
Somente em Física e Química & 0 \\
Somente em Física e Matemática & 7 \\
Somente em Química e Matemática & 0 \\
Em todas as disciplinas & 1 \\
\hline Total & 21 \\
\hline
\end{tabular}

Na Tabela 15 é mostrado que dentre os 21 alunos que foram aprovados por CC em pelo menos uma disciplina, 19 (90,5\%) foram aprovados em CC em somente uma série, sendo 18 somente na $2^{\text {a }}$ série. Destaca-se que dois alunos foram aprovados por CC na $1^{\text {a }}$ e na $2^{\mathrm{a}}$ séries. 
Tabela 15 - Número de alunos aprovados por Conselho de Classe por série na terceira turma

\begin{tabular}{lc}
\hline Disciplina(s) & Número de alunos \\
\hline Somente na $1^{\text {a }}$ série & 1 \\
Somente na $2^{\mathrm{a}}$ série & 18 \\
Somente na $3^{\mathrm{a}}$ série & 0 \\
Somente na $1^{\mathrm{a}}$ e na $2^{\mathrm{a}}$ séries & 2 \\
Somente na $1^{\mathrm{a}}$ e na $3^{\mathrm{a}}$ séries & 0 \\
Somente na $2^{\mathrm{a}}$ e na $3^{\mathrm{a}}$ séries & 0 \\
Em todas as séries & 0 \\
\hline Total & 21 \\
\hline
\end{tabular}

\subsubsection{Disciplina de Física}

Na Figura 10 é apresento o número de aprovações segundo a forma de aprovação e por ano na disciplina de Física. Observa-se que na $1^{\text {a }}$ série havia muitos alunos em RT. Nas demais séries esse número diminuiu, porém houve um grande aumento de aprovações por CC na $2^{\mathrm{a}}$ série e nenhuma na $3^{\mathrm{a}}$ série.

Figura 10 - Número de aprovações da terceira turma segundo a forma de aprovação e a série na disciplina de Física.

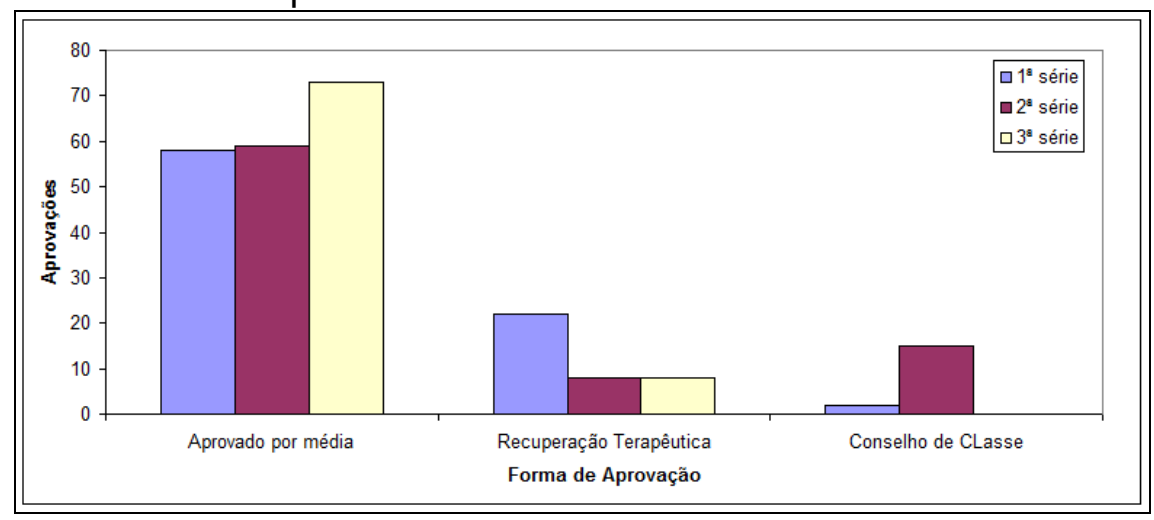

Na Tabela 16 é apresentado o desempenho dos alunos em Física durante as três séries. Observa-se que dos 82 alunos da segunda turma, 49 (68,1\%) foram aprovados por média em Física em todas as séries, 28 (34,1\%) foram aprovados na RT pelo menos em uma série, e 15 (18,3\%) foram aprovados no CC pelo menos em uma série. 
Tabela 16 - Desempenho dos alunos da terceira turma em Física durante as três séries

\begin{tabular}{lcccc}
\hline $1^{\text {a }}$ série & $2^{\text {a }}$ série & $3^{\text {a }}$ série & Número de alunos & Aprovações por CC \\
\hline AM & AM & AM & 49 & 0 \\
AM & AM & RT & 3 & 0 \\
AM & RT & AM & 2 & 0 \\
RT & AM & AM & 5 & 0 \\
RT & AM & RT & 2 & 0 \\
RT & RT & AM & 6 & 0 \\
AM & CC & AM & 3 & 1 \\
AM & CC & RT & 1 & 1 \\
RT & CC & AM & 6 & 1 \\
RT & CC & RT & 2 & 1 \\
RT & CC & RE & 1 & 1 \\
CC & CC & AM & 2 & 2 \\
\hline AM: Aprovado por Média; CC: Conselho de Classe; RT: Recuperação Terapêutica; RE: Reprovado
\end{tabular}

Com relação aos alunos aprovados por CC em Física, observa-se que: três alunos foram aprovados por média na $1^{\text {a }}$ e $3^{\text {a }}$ séries e, em CC, na $2^{\text {a }}$ série; um aluno foi aprovado por média na $1^{\text {a }}$ série, em CC na $2^{\mathrm{a}}$ e por RT na $3^{\mathrm{a}}$ série; seis alunos foram aprovados após estudos de RT na $1^{\text {a }}$ série, em CC na $2^{\mathrm{a}}$ e, por média, na $3^{\mathrm{a}}$ série; dois alunos foi aprovado após RT na $1^{\text {a }}$ e $3^{\mathrm{a}}$ séries e, em CC, na $2^{\mathrm{a}}$ série; um aluno foi aprovado após RT na $1^{\text {a }}$ série, em CC na $2^{\text {a }}$ e reprovado na $3^{\text {a }}$ série; e dois alunos foram aprovados em CC na $1^{\mathrm{a}}$ e $2^{\mathrm{a}}$ séries e, por média, na $3^{\mathrm{a}}$ série.

\subsubsection{Disciplina de Química}

Na Figura 11 é apresentado o número de aprovações segundo a forma de aprovação e por ano na disciplina de Química. Observa-se que na $1^{\text {a }}$ série havia mais alunos aprovados em RT. Na $2^{\text {a }}$ série esse número diminuiu e depois aumentou um pouco na $3^{\text {a }}$ série. Houve poucas aprovações por CC, sendo apenas duas na $1^{\text {a }}$ série. De um modo geral, parece que a $1^{\text {a }}$ série foi a mais difícil para os alunos. 
Figura 11 - Número de aprovações da terceira turma segundo a forma de aprovação e a série na disciplina de Química.

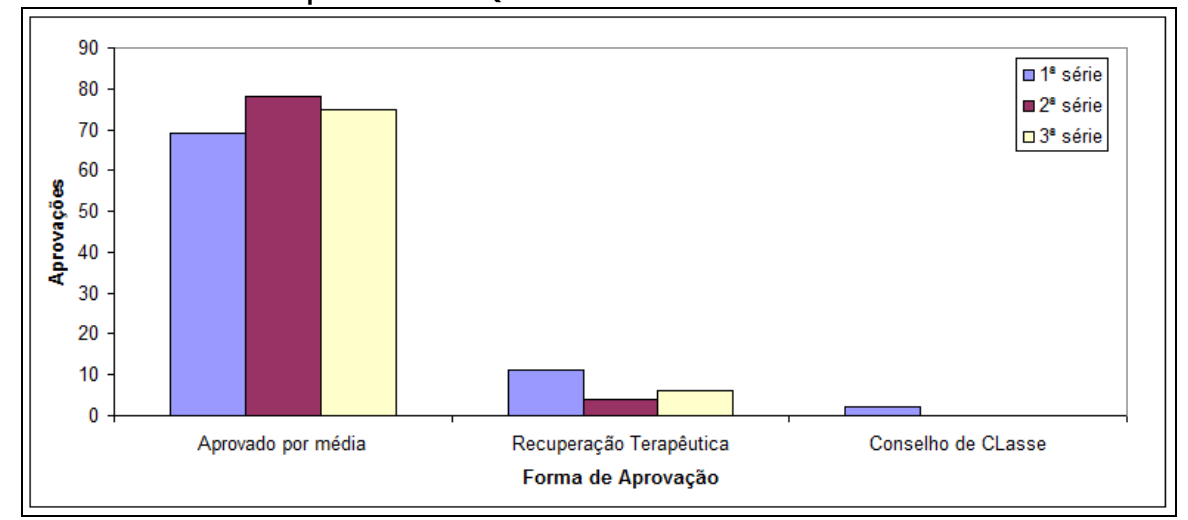

Na Tabela 17 é apresentado o desempenho dos alunos em Química durante as três séries. Observa-se que dos 128 alunos da primeira turma, 95 (74,2\%) foram aprovados por média em Química em todas as séries, 31 (24,2\%) foram aprovados na RT pelo menos em uma série, e 8 (6,2\%) foram aprovados no CC pelo menos em uma série.

Tabela 17 - Desempenho dos alunos da terceira turma em Química durante as três séries

\begin{tabular}{lllll}
\hline $1^{\text {a }}$ série & $2^{\text {a }}$ série & $3^{\text {a }}$ série & Número de alunos & Aprovações por CC \\
\hline AM & AM & AM & 61 & 0 \\
AM & AM & RT & 6 & 0 \\
AM & RT & AM & 1 & 0 \\
RT & AM & AM & 9 & 0 \\
RT & RT & AM & 2 & 0 \\
AM & RT & RE & 1 & 0 \\
CC & AM & AM & 2 & 1 \\
\hline \multicolumn{2}{c}{ AM: Aprovado por Média; CC: Conselho de Classe; RT: Recuperação Terapêutica; RE: Reprovado }
\end{tabular}

Com relação aos alunos aprovados por CC em Química, observa-se que apenas dois alunos foram aprovados em Conselho de Classe na $1^{\text {a }}$ série e, por média, na $2^{\mathrm{a}} \mathrm{e}$ $3^{a}$ séries. Destaca-se que o aluno reprovado em Química na $3^{\mathrm{a}}$ série foi aprovado por média na $1^{\mathrm{a}}$ série e por RT na $2^{\mathrm{a}}$ série.

\subsubsection{Disciplina de Matemática}

Na Figura 12 é apresentado o número de aprovações segundo a forma de aprovação e por ano na disciplina de Matemática. Observa-se que não houve muita diferença entre a $2^{\mathrm{a}}$ e a $3^{\mathrm{a}}$ série em termos de forma de aprovação, no entanto, na $3^{\mathrm{a}}$ 
série houve um aumento visível de AM e uma queda em aprovações por RT e em CC, sugerindo que essa série pode ter sido mais fácil do que as demais.

Figura 12 - Número de aprovações da terceira turma segundo a forma de aprovação e a série na disciplina de Matemática.

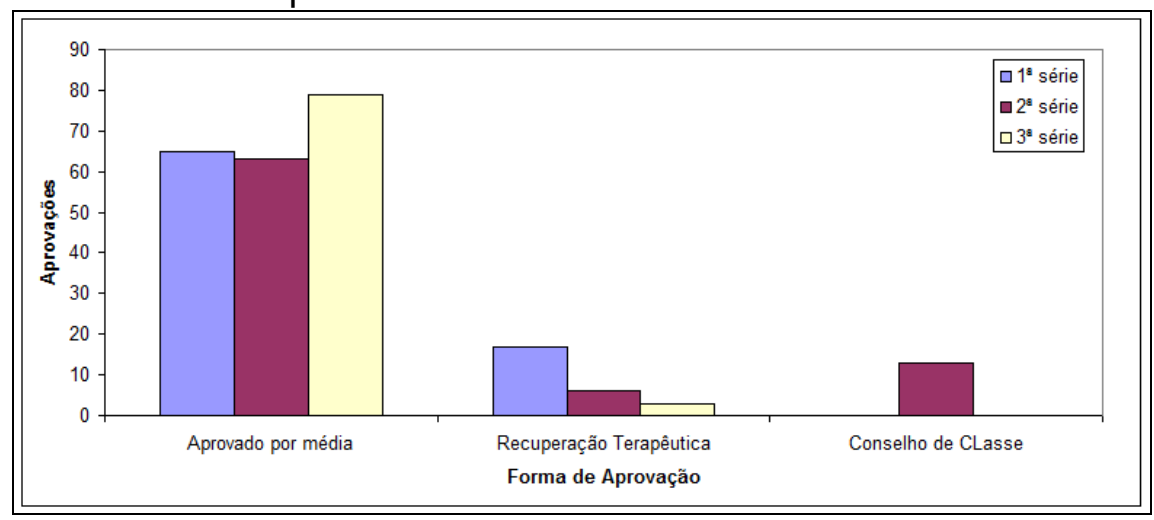

Na Tabela 18 é apresentado o desempenho dos alunos em Matemática durante as três séries. Observa-se que dos 128 alunos da primeira turma, 80 (62,5\%) foram aprovados por média em Matemática em todas as séries, 46 (35,9\%) foram aprovados na RT pelo menos em uma série, e $14(10,9 \%)$ foram aprovados no CC pelo menos em uma série.

Tabela 18 - Desempenho dos alunos da terceira turma em Matemática durante as três séries

\begin{tabular}{lllll}
\hline $1^{\text {a }}$ série & $2^{\text {a }}$ série & $3^{\text {a }}$ série & Número de alunos & Aprovações por CC \\
\hline AM & AM & AM & 52 & 0 \\
AM & AM & RT & 2 & 0 \\
AM & RT & AM & 4 & 0 \\
RT & AM & AM & 9 & 0 \\
RT & RT & AM & 2 & 0 \\
AM & CC & AM & 6 & 1 \\
AM & CC & RT & 1 & 1 \\
RT & CC & AM & 6 & 1 \\
\hline \multicolumn{2}{l}{ AM: Aprovado por Média; CC: Conselho de Classe; RT: Recuperação Terapêutica }
\end{tabular}

Com relação aos alunos aprovados por CC em Matemática, observa-se que: seis alunos foram aprovados por média na $1^{\text {a }}$ e $3^{\text {a }}$ séries e, em CC, na $2^{\text {a }}$ série; um aluno foi aprovado por média na $1^{\text {a }}$ série, em CC, na $2^{\text {a }}$ série, e por RT na $3^{\text {a }}$ série; e seis alunos foram aprovados após estudos de RT na $1^{\text {a }}$ série, em CC na $2^{\mathrm{a}}$ e, por média, na $3^{\mathrm{a}}$ série. 


\section{CONCLUSÃO}

O Projeto Educativo do Colégio Marista Santa Maria tem entre seus principais objetivos instrumentalizar e melhorar a formação dos educadores que não estejam preocupados apenas com a formação parcial de seus alunos, mas, sim, com a sua formação integral.

Os resultados mostraram que a disciplina que mais aprovou em Conselho de Classe, no geral, no período analisado foi a disciplina de Física, seguida da disciplina de Matemática, sendo a disciplina de Química a que menos aprovou por CC. As promoções em Conselho de Classe não comprometeram totalmente o desempenho desses alunos na(s) série(s) seguinte(s), embora grande parte deles seja aprovada nas séries seguintes por RT ou CC. No entanto, para a maioria, funcionou como estímulo para o prosseguimento dos seus estudos.

Verificou-se que o número de aprovações por Conselho de Classe, segundo a série e a disciplina, não foi o mesmo nas três turmas analisadas, sendo que a terceira turma apresenta um comportamento bem diferente da primeira e da segunda turmas. Na época da realização desse estudo não foi investigada qual seria a causa dessa diferença observada na análise, no entanto, algumas possibilidades poderiam influenciar nisso, tal como, o material pedagógico e as práticas pedagógicas podem ter sido alterados ao longo desses três anos nas três turmas, pode ter ocorrido troca de professores ou as turmas que entram em anos diferentes poderiam possuir características populacionais diferentes (nível de proficiência, aspectos cognitivos, procedência escolar, etc.).

O trabalho desenvolvido no Colégio Marista Santa Maria em relação ao Conselho de Classe é importante, pois possibilita estabelecer critérios e concepções comuns entre os professores, facilitando a melhor compreensão do educando e dos aspectos que envolvem o ensino-aprendizagem.

Sugere-se que este trabalho seja ampliado para as demais disciplinas constantes da grade curricular do Ensino Médio desta escola, para verificar se elas possuem o mesmo comportamento das disciplinas analisadas. 
Sugere-se, também, que este estudo, seja desenvolvido em outras escolas, tanto da rede particular quanto da rede pública, para verificar se os alunos aprovados em Conselho de Classe apresentam comportamento e/ou aproveitamento similar(es) ao(s) constatados nos alunos do Ensino Médio do Colégio Marista Santa Maria no período de 1996 a 2000. 


\section{REFERÊNCIAS}

HAYDT RCC. Avaliação do Processo Ensino - Aprendizagem. 5 ed. São Paulo: Ática, 1995.

PERINI et al. Conselho de Classe. Porto Alegre: Secretaria de Educação. 1982.

SANT'ANNA IM, WERNECK H. Concepções sobre conselho de classe. 1995.

SAUL AM. Avaliação emancipatória. 2 ed. São Paulo: Cortez, 1991.

VASCONCELLOS CS. Avaliação concepção dialética libertadora do processo de avaliação escolar. São Paulo: Escolas Profissionais Salesianas, 1993.

WERNECK H. Ensinamos demais, aprendemos de menos. Petrópolis: Vozes, 1998. 